Eur. J. Clin. Chem. Clin. Biochem.

Vol. 31, 1993, pp. 675-678

(C) 1993 Walter de Gruyter \& Co.

Berlin - New York

\title{
The Molecular Basis of Hereditary Fructose Intolerance in Italian Children ${ }^{1)}$
}

\author{
By Rita Santamaria ${ }^{1}$, Maria Irene Scarano ${ }^{1}$, Gabriella Esposito ${ }^{1}$, L. Chiandetti $^{2}$, Paola Izzo $^{1}$ and F. Salvatore $^{1}$ \\ ${ }^{1}$ Dipartimento di Biochimica e Biotecnologie Mediche, Facoltà di Medicina e Chirurgia, Università di Napoli \\ Federico II, Naples, Italy \\ ${ }^{2}$ Clinica Pediatrica, Università di Padova, Italy
}

(Received March 30/July 5, 1993)

Summary: We investigated the molecular defects of the aldolase B gene in five unrelated patients affected by hereditary fructose intolerance. The techniques used were DNA amplification, direct sequencing and allelespecific oligonucleotide (ASO) hybridization. The most frequent substitutions found in the hereditary fructose intolerance alleles analysed were the A174D and the A149P mutations, which account for $50 \%$ and $30 \%$ of the alleles, respectively. In two unrelated families, we found a rare mutation, the MD $\Delta 4$ previously described only in one British family, which may be an important cause of the disease in Italy.

\section{Introduction}

Hereditary fructose intolerance, inherited as an autosomal recessive character, is an inborn error of carbohydrate metabolism caused by a deficiency of hepatic aldolase $\mathrm{B}^{2)}(1,2)$. The disease is heterogeneous at the molecular level and analysis of the relative DNA mutations may allow an early diagnosis in infants and identification of the carrier status. This would avoid the routinely performed intravenous fructose tolerance test or the direct assay of aldolase activity in liver biopsy samples.

The aldolase B gene, located on chromosome 9 (3), is $14.5 \cdot 10^{3}$ bases long and consists of nine exons coding for a protein of 365 amino acid residues (4). Ten mutations have been described to-date; of these the most common are two single-base substitutions (A149P and A174D) in exon 5 (5). The A149P mutation leads to a protein with greatly diminished activity towards the fructose-1-phosphate and fructose1,6-bisphosphate substrates, while the A174D muta-

1) Funding Organizations: Consiglio Nazionale delle Ricerche (CNR); Ministero dell'Università e della Ricerca Scientifica e Tecnologica (MURST); Regione Campania.

$\left.{ }^{2}\right)$ Enzyme: Fructose-bisphosphate aldolase, EC 4.1.2.13 tion leads to a highly unstable protein. Other recently described mutations are rare and, in some cases, confined to single affected pedigrees $(6-10)$. In this study we have analysed the aldolase $B$ gene in five unrelated hereditary fructose intolerance patients from Northern Italy, using the DNA polymerase chain reaction followed by sequencing and hybridization to specific oligonucleotides. Furthermore, carrier status was established in three individuals, who are siblings of two probands.

\section{Materials and Methods}

Southern blot and hybridization

DNA, extracted from peripheral blood according to conventional methods (11), was digested with Eco RI and Bgl II, electrophoresed on $1 \%$ agarose gel and blotted according to the Southern method (12). The nylon membranes (Nytran, Schleicher \& Schuell, Germany) were then hybridized to the human aldolase B cDNA (13) probe previously labelled by nick translation with $\left[\alpha-{ }^{32}\right.$ P]dATP.

\section{Oligonucleotide synthesis}

The oligonucleotides for amplification and allele-specific oligonucleotide hybridization were made on an Applied Biosystems 391 DNA synthesizer (Warrington, UK). 


\section{Amplification}

Genomic DNA $(1 \mu \mathrm{g})$ was amplified in a Perkin Elmer Thermal Cycler Apparatus (Cetus, USA) using $100 \mathrm{pmol}$ of each primer, $200 \mu \mathrm{mol} d$ NTPs and 'standard' PCR buffer. Thirty PCR amplification cycles were performed at the following reaction temperatures: denaturation at $93^{\circ} \mathrm{C}$ for $2 \mathrm{~min}$, annealing at $55^{\circ} \mathrm{C}$ for $3 \mathrm{~min}$ and extension at $72^{\circ} \mathrm{C}$ for 3 min using $2.5 \mathrm{U}$ of Taq DNA polymerase; the final incubation time was $10 \mathrm{~min}$ at $72{ }^{\circ} \mathrm{C}$. The sequences of the primers used are shown in table 1.

Tab. 1. Primers for amplification of human aldolase B coding exons

\begin{tabular}{llll}
\hline $\begin{array}{l}\text { Coding } \\
\text { exons }\end{array}$ & Sequence $\left(5^{\prime}-3^{\prime}\right)$ & $\begin{array}{l}\text { Size } \\
\text { (base } \\
\text { pairs) }\end{array}$ \\
\hline EX 2 & 2.1 & GAGCCACCCATGGTTCTGTG & 202 \\
& 2.2 & GTTGTTATATGATGAGACTG & \\
EX 3 & 3.1 & CTAACTAGCCACCTGAGAGC & 544 \\
& 3.2 & TCTCTGTGGGAAGATGACGA & \\
EX 4 & 4.1 : & GATGCAAACTGTTAGTTAG & 190 \\
& 4.2 & GCCTTCATTTCTAGCTTAC & \\
EX 5 & 5.1 & TAGAAGCCCCATGGATCAGG & 274 \\
& 5.2 & GAAGAAAACTCTAGCCTACT & 260 \\
EX 6 & 6.1 & GAAAAATTCTACTGTCTTTA & 269 \\
& 6.2 & AGAATTGGGGCCTTCATAT & \\
EX 7 & 7.1 & GTGGGACCTCTTGTCCTT & 265 \\
& 7.2 & ACAAACAGAAAGCTTGTGGC & \\
EX 8 & 8.1 & TCATTGCTTGCTTTCTCAAGC & 355 \\
& 8.2 & AAGAAAACAATGCTTCTCCG & 279 \\
EX 9 & 9.1 & AGTGAAGGTTTGACTGGT & \\
& 9.2 & TGTCGAATTTCCAGGATT & \\
\hline
\end{tabular}

\section{Sequencing}

The amplified double-stranded fragments were excised from a $1.5 \%$ low melting agarose gel (NuSieve GTG, FMC, USA) and directly sequenced using Sequenase version 2.0 (U.S. Biochemical) according to the manufacturer's instructions. Alternatively, the amplified DNAs were cloned into M13mp18 vector and sequenced with the Sanger method (14).

\section{Dot blotting}

About $100 \mathrm{ng}$ of amplified DNA corresponding to exons 4 and 5 were denatured with $0.4 \mathrm{~mol} / \mathrm{l} \mathrm{NaOH}$ and $0.025 \mathrm{~mol} / 1 \mathrm{EDTA}$, then blotted onto nylon membranes (Nytran, Schleicher \& Schuell, Germany). The filters were then hybridized in $0.9 \mathrm{~mol} / \mathrm{l}$ sodium chloride, $0.09 \mathrm{~mol} / 1$ sodium citrate, $\mathrm{pH} 7.0,5$ times concentrated Denhart's solution, $5 \mathrm{~g} / \mathrm{l} \mathrm{SDS}$, and $50 \mathrm{mg} / \mathrm{l}$ salmon sperm DNA, containing either the wild type or mutant oligonucleotide as probe, $\left[\gamma-{ }^{32} \mathrm{P}\right] \mathrm{dATP}$ end-labelled. The hybridization and the discriminatory washing temperatures depended on the melting temperature $\left(T_{m}\right)$ of the oligonucleotides used as probes. The filters were autoradiographed at $-80^{\circ} \mathrm{C}$ using an intensifying screen. The sequence of the probes used are listed below:

A149WT, AAGTGGCGTGCTGTGCTGA; A149MUT, AAGTGGCGTCCTGTGCTGA; A174WT, TCGCTACGCCAGCATCT; A174MUT, AGATGCTGTCGTAGCGA; MDA4WT, GCAGGAACAAACAAAGAAAC; MDA4MUT, GCAGGAACAAAGAAACCACC;

\section{Results and Discussion}

We investigated the molecular basis of hereditary fructose intolerance in five unrelated Italian children, diagnosed by enzymatic assay 'of liver biopsies. The homozygote condition of large deletions or insertions was excluded in all patients by Southern blot analysis (see fig. 1). DNAs from five subjects and one control, extracted from peripheral blood, were digested with $E c o$ RI and $B g l$ II, and, after Southern blot, hybridized to the human aldolase B cDNA as probe (13). We amplified the whole coding region (exons 2-9) of the aldolase B gene with PCR using specific primers (see tab. 1). To screen for the most common mutations, A149P and A174D, we sequenced the amplified exon 5 in all patients. The results showed that one patient (No. 3) was homozygous for the A149P mutation, one (No. 5) was homozygous for the A174D mutation, and another (No. 1) was a compound heterozygote for the A174D and the A149P mutations. The other two subjects (Nos. 2 and 4) were compound heterozygotes for A174D and for another mutation in a different region of the aldolase $B$ gene. To identify this mutation, all the exons of these subjects were analysed by PCR and sequencing. In both patients we found a mutation in exon $4(\mathrm{MD} \Delta 4)$. This mutation, so far described in only one British family, is a 4-base pair deletion in exon 4 that causes a frameshift at codon 118; this results in an early stop codon that gives rise to a truncated protein of 150 residues (6). The alleles bearing the different mutations in the compound heterozygotes (patients Nos. 2 and 4) were cloned and sequenced. The sequence of the normal allele and the mutant allele containing the MD $\Delta 4$ mutation is shown in figure 2 .

The aldolase B mutations in our patients were also analysed by hybridization to oligonucleotides specific for the wild and mutant sequences (allele-specific oligonucleotides). The results obtained with the slot blot hybridization are shown in figure 3.

Our survey indicates a high incidence of the A174D mutation in our patients. In fact, this mutation accounts for $50 \%$ of 10 independent hereditary fructose intolerance alleles, while the A149P mutation accounts for $30 \%$ and the MD $\Delta 4$ for $20 \%$.

In all the families, direct sequence analysis on amplified exons 4 and 5 of the parents of the five probands indicates Mendelian inheritance for both of the $\mathrm{mu}$ tant alleles found in each patient (data not shown). The molecular alteration found in each of the two parents excludes the possibility that propositi Nos. 3 and 5 are hemizygotes, one allele being largely deleted. Furthermore, in two families, carrier analysis was 


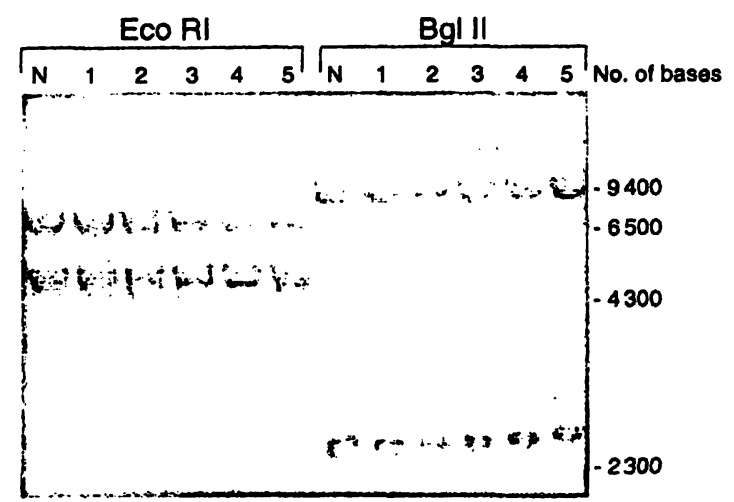

Fig. 1. Southern blot analysis.

DNAs from a normal subject $(\mathrm{N})$ and five $(1-5)$ hereditary fructose intolerance patients digested with $E c o$ $\mathrm{RI}$ and $\mathrm{Bgl}$ II were hybridized to the aldolase B CDNA. The size marker is indicated on the right.

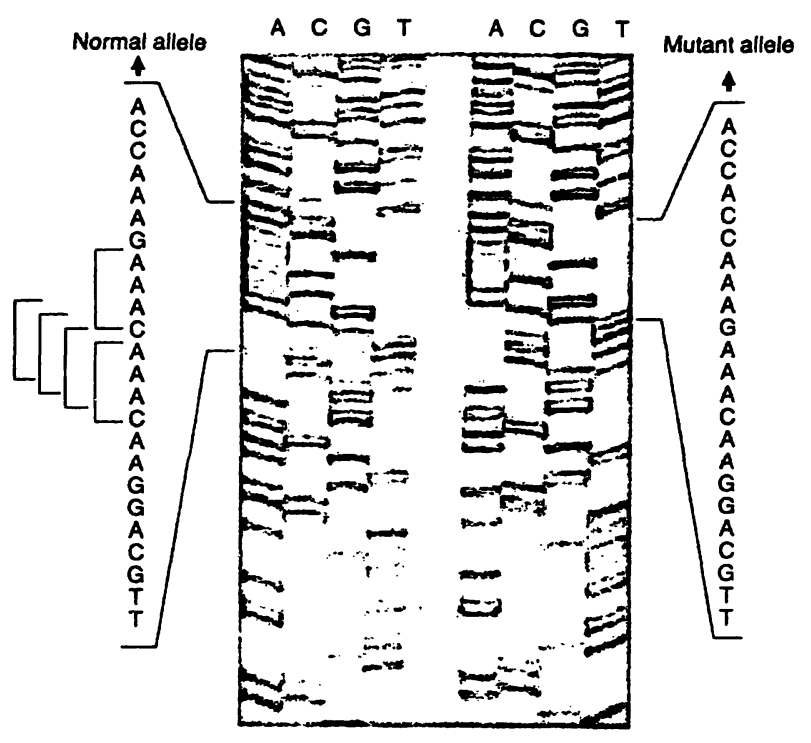

Fig. 2. $\Delta 4$ mutation in exon 4 .

Sequences of normal cloned M13 (left) and mutant alleles (right), after amplification of exon 4 from subject No. 2. The brackets indicate the alternative 4 base pair deletions leading to the missing CAAA sequence in the mutant allele.

performed in three individuals (siblings of the two probands), and in all three carrier status was diagnosed for the A174D mutation.

The results described in this paper are in agreement with the mutational heterogeneity of hereditary fructose intolerance $(15,16)$ and indicate a higher frequency of the A174D mutation in our Italian patients. Although the latter finding may appear to diverge slightly from the frequencies described for the two mutations (15), it should be taken into account that only a small number of individuals have been so far investigated. Moreover, our data are in agreement with the decreasing frequency of the A149P mutation
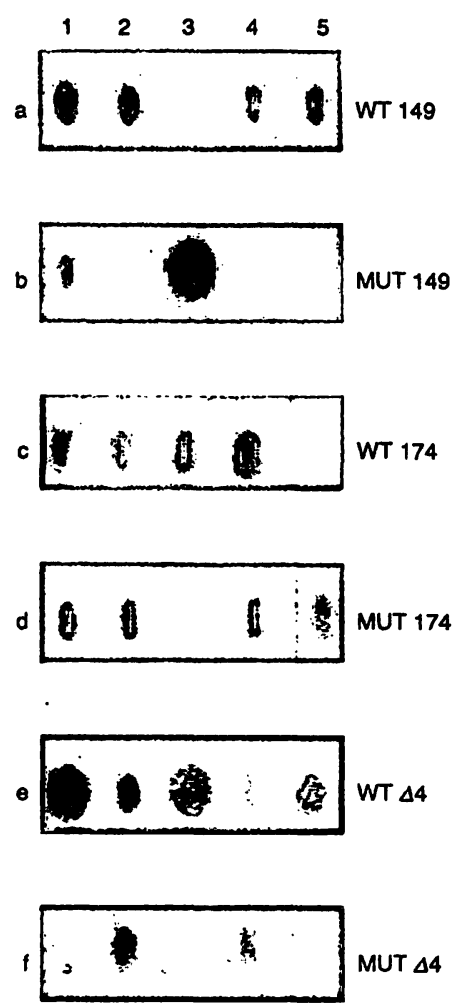

Fig. 3. Genotype analysis of hereditary fructose intolerance patients.

Hybridization of PCR amplified DNAs to normal (wt 149, wt 174 and wt $\Delta 4$ in lanes a, c and e) and mutant probes (mut 149, mut 174 and mut $\Delta 4$ in lanes $b, d$ and f). $1-5$ are the five patients analysed.

from north to south in Europe (15). The MD $\Delta 4$ mutation, so far considered rare, was found in two unrelated Italian families and might be another important cause of the disease in Italy. This mutation should be taken into account, together with other rare mutations found in some Italian families (16), in the diagnosis and genetic counselling of heterozygotes.

In conclusion, the combination of $\mathrm{PCR}$ followed by direct sequencing or by allele-specific oligonucleotide hybridization is a rapid and efficient method for the prenatal and early diagnosis of hereditary fructose intolerance and for the screening of asymptomatic carriers in affected families, at least at all sites where mutations have been identified. Hitherto, this condition was diagnosed by the cumbersome and invasive technique of liver biopsy, and by the intravenous fructose tolerance test.

\section{Acknowledgements}

This work was supported by grants from CNR (Rome), Target projects Biotechnology and Bioinstrumentations, Ingegneria Genetica, from MURST, and from Regione Campania. 


\section{References}

1. Salvatore, F., Izzo, P. \& Paolella, G. (1986) Aldolase gene and protein families: Structure, expression and pathophysiology. In: Human genes and diseases, horizons in biochemistry and biophysics (Blasi, F., ed.) pp. 611-665, J. Wiley \& Sons, Ltd., New York.

2. Gitzelmann, R., Steinmann, B. \& Van den Berghe, G. (1989) Disorders of fructose metabolism. In: The metabolic basis of inherited disease, 6th edn. (Scriver, C. R., Beaudet, A. L., Sly, W. S. \& Valle, D., eds.) pp. 399-424, McGrawHill, New York.

3. Henry, I., Gallano, P., Besmond, C., Weil, D., Mattei, M. G., Turleau, C., Bouè, J., Kahn, A. \& Junien, C. (1985) The structural gene for aldolase B (ALDB) maps to $9 q 13$ $\rightarrow$ 32. Ann. Hum. Genet. 49, 173-180.

4. Tolan, D. R. \& Penhoet, E. E. (1986) Characterization of the human aldolase B gene. Mol. Biol. Med. 3, 245-264.

5. Cross, N. C. P. \& Cox, T. M. (1990) Hereditary fructose intolerance. Int. J. Biochem. 22, 685-689.

6. Dazzo, C. \& Tolan, D. R. (1990) Molecular evidence for compound heterozygosity in hereditary fructose intolerance. Am. J. Hum. Genet. 46, 1194-1199.

7. Kajihara, S., Tsunehiro, M., Arai, Y., Owada, M., Kitagawa, T. \& Hori, K. (1990) Hereditary fructose intolerance caused by a nonsense mutation of the aldolase B gene. Am. J. Hum. Genet. 47, 562-567.

8. Cross, N. C. P. \& Cox, T. M. (1990) Partial aldolase B gene deletions in hereditary fructose intolerance. Am. J. Hum. Genet. 47, 101-106.

9. Cross, N. C. P., Stojanov, L. M. \& Cox, T. M. (1990) A new aldolase B variant, $\mathrm{N} 334 \mathrm{~K}$, is a common cause of hereditary fructose intolerance in Yugoslavia. Nucl. Acids Res. 18, 1925.
10. Brooks, C. C., Buist, N., Tuerck, J. \& Tolan, D. R. (1991) Identification of a splice-site mutation in the aldolase $B$ gene from an individual with hereditary fructose intolerance. Am. J. Hum. Genet. 49, 1075-1081.

11. Sambrook, J., Fritsch, E. F., Maniatis, T. (1989) Molecular cloning: A laboratory manual, 2nd edn. Cold Spring Harbor Laboratory, Cold Spring Harbor, NY.

12. Southern, E. (1975) Detection of specific sequences among DNA fragments separated by gel electrophoresis. J. Mol. Biol. 98, 503-517.

13. Paolella, G., Santamaria, R., Izzo, P., Costanzo, P. \& Salvatore, F. (1984) Isolation and nucleotide sequence of a full-length c-DNA coding for aldolase B from human liver. Nucl. Acids Res. 12, $7401-7410$.

14. Sanger, F., Nicklen, S. \& Coulson, A. R. (1977) DNA sequencing with chain-terminating inhibitors. Proc. Natl. Acad. Sci. USA 74, 5463 - 5487 .

15. Cross, N. C. P., de Franchis, R., Sebastio, G., Dazzo, C., Tolan, D. R., Gregori, C., Odievre, M., Vidailhet, M., Romano, V., Mascali, G., Musumeci, S., Steinmann, B., Gitzelmann, R. \& Cox, T. M. (1990) Molecular analysis of aldolase $\mathrm{B}$ genes in hereditary fructose intolerance. Lancet $335,306-309$.

16. Sebastio, G., de Franchis, R., Strisciuglio, P., Andria, G., Dionisi Vici, C., Sabetta, G., Gatti, R., Cross, N. C. P. \& Cox, T. M. (1991) Aldolase B mutations in Italian families affected by hereditary fructose intolerance. J. Med. Genet. $28,241-243$.

Prof. F. Salvatore

Dipartimento di Biochimica

e Biotecnologie Mediche

Facoltà di Medicina e Chirurgia

Università di Napoli Federico II

via $S$. Pansini 5

I-80131 Naples

Italy 